\title{
La construcción de la pertenencia sufí en el contexto cultural argentino y los hilos de la trama transnacional
}

\author{
Construction of sufi membership in the argentine cultural \\ context and transnational network \\ LUCÍA AMPARO E. SALINAS \\ Universidad Nacional de Rosario
}

RECEPCIÓN: 05/03/20I 5 • ACEPTACIÓN: 23/06/20I 5

RESUMEN En el presente trabajo se aborda la construcción de la pertenencia de los grupos sufíes Naqshbandi Haqqani en el entramado cultural de Argentina. Dicho análisis se realiza a la luz de los procesos de transnacionalización religiosa, ya se trate del resultado de la circulación de objetos y símbolos de significancia sufi por promotores individuales, o la red de (re) localizaciones de espacios sufies en territorios locales. Para la realización de este análisis nos hemos valido de las líneas de relato histórico de las distintas turuq argentinas pertenecientes a esta orden, como de las circunstancias en las que se teje la pertenencia en la actualidad. Dicho trabajo se sustenta a partir de entrevistas a miembros y observaciones en distintas comunidades. Para pensar la manera en que se constituye la pertenencia de estos grupos, retomamos discusiones sobre la relación entre la cultura y la identidad, o más bien sobre la dislocación de esa relación.

Palabras Clave Orden Sufi Naqshbandi Haqqani de Argentina, transnacionalización religiosa, cultura, identidad.

ABSTRACT The purpose of this paper is to analyze the construction of the 
membership of the Naqshbandi Haqqani sufi groups in the argentine cultural network. This analysis is done in the light of religious transnational processes, so far as the result of the movement of objects and symbols of sufi significance by individual developers, or network of (re) locations sufi spaces in local territories. To carry out this investigation we have used the historical narrative of several Argentine turuq belonging to this order, as well also the circumstances in which membership takes place nowadays. This work is supported on observations and in-depth interviews with engaging members from different communities. To reflect how the membership of these groups occurs, we evoke the discussions about relationship between culture and identity, or rather the dislocation of that relationship.

KEYWORDS Naqshbandi Haqqani Sufi Order of Argentina, religious transnationalization, culture, identity.

\section{Introducción}

El análisis de las religiones transnacionales en la actualidad representa múltiples desafíos. Vertebradas en circunstancias potenciadas en la contemporaneidad, tales como la expansión de los medios de comunicación y la creciente fluidez en el traslado de comunidades e individuos diversos por todo el planeta, nos instan a observar sus desarrollos locales en el marco de este panorama global móvil.

En este trabajo, un desprendimiento del trabajo de tesis doctoral en estado de proceso, pretendemos echar luz sobre las formas en que se construye la pertenencia a una comunidad religiosa minoritaria. Nos referimos a la comunidad sufí Naqshbandi Haqqani en Argentina. Analizaremos un conjunto de prácticas y creencias religiosas que reúnen a este grupo de personas por fuera de los centros geográficos y simbólicos de referencia de esas prácticas, observando como convergen procesos locales y transnacionales religiosos, a partir de los modelos de transnacionalización de productos y prácticas religiosas, y la (re)construcción del «lugar» o localidad derivados de puntos geográficos específicos.

Tendremos en cuenta la relación conceptual entre cultura e identidad, como la propone Grimson (20I0), como no homogénea ni con límites compartidos, intentando despejar en el campo analizado los elementos que se corresponden con uno y con el otro. 
Apreciaremos la construcción de la pertenencia sufí más que como fruto del contacto e interrelación de entidades y prácticas religiosas discretas, como un complejo de relaciones que envuelven personas, objetos y acciones religiosas. Ya en 1997 Clifford mencionaba que en antropología «los nuevos paradigmas teóricos articulan explícitamente los procesos locales y globales utilizando relaciones, no teologías», y que «los enfoques basados en el contacto no presuponen totalidades socioculturales que luego se relacionan, sino más bien sistemas ya constituidos de ese modo, que pasan a integrar nuevas relaciones a través de procesos históricos de desplazamiento» (Clifford, I999: I8). Dicha perspectiva, entendemos, dota de vitalidad al conjunto de prácticas que deseamos analizar, en tanto el pensar la posibilidad de contacto en términos de sistemas nos permite mayor flexibilidad y variabilidad en ese contacto, plasmándolo además en un proceso en el tiempo.

El presente escrito se sustenta en el abordaje de las comunidades de la mencionada Tariqa, en las localidades de Rosario y San Lorenzo (Santa Fe), La Consulta (Mendoza), El Bolsón (Río Negro) y Mar del Plata (Buenos Aires). Se ha realizado el análisis de las tres primeras comunidades a partir del trabajo de campo, consistente en observaciones y entrevistas en profundidad, realizado durante los años 20 I I y parte del 20I2, y a partir de material de difusión y entrevistas a miembros para el caso de las dos últimas comunidades.

\section{Islam y sufismo en el mapa religioso argentino}

La religión y las comunidades religiosas han sido un objeto preciado para las ciencias sociales en Argentina y en la región, aunque desde la década de los ochenta se ha podido observar un abordaje con fuerza creciente de la diversidad religiosa. En aquel momento, algunos investigadores locales retomaron, para explicar este proceso de apertura, el concepto de «nuevos movimientos religiosos", presuponiendo un período anterior monopolizado por el catolicismo. Luego, esta visión fue problematizada considerando que tal vez dicha explosión sólo se trataba de una novedad para las ciencias sociales, y en ocasiones para determinadas ciencias sociales, y que era incluso posible dudar de un pasado en el que el catolicismo hubiera sido totalizador en las subjetividades de la población argentina (Frigerio, 2007, 2013).

Si bien Argentina es un país donde la mayoría de su población sigue autodenominándose católica, debe mencionarse que existe una disminución de la presencia de dicha adscripción en el campo religioso nacional si comparamos 
estos datos con el último censo nacional que incluyó la variable (año I960) ${ }^{1}$ y que es posible mencionar interesantes datos acerca de la flexibilidad en esa adscripción, o de la no correspondencia entre adscripción (autonominación) y prácticas (participación en diferentes experiencias religiosas, católicas y no).

La Primera Encuesta Nacional sobre Creencias y Actitudes Religiosas en Argentina (CEIL-CONICET, UBA, UNR, UNCUYO, UNSE), llevada a cabo en el año 2008, reafirma la mayoría de católicos (76,5\%), le sigue un I I,3\% de indiferentes religiosos, un 9,०\% de evangélicos, un 2,0\% de Testigos de Jehová/mormones, y un I,2\% que comprenden otras religiones (Mallimaci, 20I3).

Sobre esta última cifra, el I, $2 \%$ es compartida por creyentes del judaísmo, el umbandismo, el budismo y el Islam. Los márgenes en los que se desarrollan las minorías religiosas nos ayudan a visibilizar los puntos de fuga, los dobleces de la diversidad religiosa en los que comunidades de sujetos construyen su pertenencia a agrupaciones religiosas por fuera del marco cultural dominante, que en el ámbito religioso local está vertebrado por el catolicismo.

El Islam y el sufismo, particularmente, se erigen en una minoría religiosa en el país de análisis desde la llegada de las primeras comunidades árabes desde fines del siglo XIX y principios del siglo XX. Si bien hay diferencias en cuanto a la consideración de la cifra de inmigrantes, distintos autores sostienen coincidentemente que del total del grupo inmigrante a nuestro país a principios del siglo XX, una minoría era musulmana (aproximadamente un I $5 \%$ ) frente a los cristianos y judíos. ${ }^{2}$ Montenegro (2008) menciona algunas instituciones confesionales árabes de fines del siglo XIX en el país que reafirman la minoría musulmana entre esta población. ${ }^{3}$

I. El Censo de ese año indicó que el 90,48\% de la población se autoadscribía al catolicismo.

2. Sobre este tema pueden consultarse Bianchi (2009: I34), que brinda números estimados de inmigrantes del Imperio Turco a fines del siglo XIX (el 22\% serían musulmanes y drusos), y de Turquía en tiempos más recientes. En Akmir (20II) se puede obtener información sobre inmigraciones palestinas y libanesas, entre otras, así como la inmigración en masa de sirios luego de i 880. En estos trabajos a su vez se hallarán estimaciones de las proporciones de musulmanes entre esa población.

3. La autora se refiere al establecimiento de instituciones de árabes cristianos, tales como la Iglesia Católica Apostólica Ortodoxa del Patriarcado de Antioquía (cuya catedral es San Jorge) en I927, la Iglesia San Marón, de la comunidad maronita de 
La década de los ochenta es significativa para nuestro análisis por los cambios observados en la población musulmana al interior de Argentina. Para algunos autores se trata de una proyección pública como comunidad (Bianchi, 2009); para otros se produce una reconfiguración del panorama islámico fundándose en algunas nuevas mezquitas y asociaciones, tanto shiítas como sunitas (Montenegro, 2009); y/o tiene lugar un intento de unificación políticoreligioso del Islam en el país (Forni y otros, 2003).

En la década siguiente, la comunidad musulmana debe afrontar nuevas situaciones. Durante los noventa, representantes institucionales del Islam local adquieren visibilidad pública y mediática a partir de los sucesos de dos atentados contra instituciones judías ${ }^{4}$ (Montenegro, 20II). ${ }^{5}$ En ese momento, algunos de ellos se exponen en los medios de comunicación en defensa de sus entidades.

En la actualidad, en nuestro país existen distintas instituciones del Islam pertenecientes a las ramas sunitas, shiítas, alauitas, sufíes, etcétera, numerosas asociaciones culturales y religiosas musulmanas y mezquitas. ${ }^{6}$

Buenos Aires, cuya comunidad llega al país a fines del siglo XIX, y la Iglesia Siriana Ortodoxa. Por su parte, los árabes musulmanes fundan, en la misma década, el Centro Islámico Argentino y la Asociación Pan Alauita de Beneficencia, creada en I929.

4. El atentado a la Embajada de Israel en Argentina se produjo en el año I992, y el atentado a la Asociación Mutual Israelita Argentina (AMIA) en el año I994.

5. Además de un aumento de la visibilización institucional, también mencionada por la autora con la creación entre otros del Centro Islámico de Palermo y la mezquita Rey Fahd inaugurado en el año 2000.

6. Algunos de estos datos son mencionados por Forni y otros (2003). Para la Ciudad de Buenos Aires: Centro Cultural Islámico Custodio de las Dos Sagradas Mezquitas Rey Fahd en Buenos Aires; Mezquita Al- Ahmad; Centro Islámico de la República Argentina; Asociación Civil Cultural Yerrahi para la Difusión del Islam (Orden Sufi Yerrahi Al Halveti; fundado y dirigido por Sheij Orhan Baba Al-Yerrahí); Orden Halveti Jerrahi Argentina; Fundación de la Amistad Argentina Turca; Asociación Islámica la Unión Alauita, Asociación Naqshbandi Haqqani de Argentina. En el resto de la provincia de Buenos Aires: Asociación Fe de Islam; Asociación Islámica Alauita (José Ingenieros); Asociación Islámica Al Hagg Yusif (Bs. As); Asociación Islámica Árabe Argentina (Bs. As.); Asociación Islámica Drusa de Beneficencia (Bs. As); Asociación Yabrudense (Bs. As); Asociación de Sufismo para Latinoamérica Orden de Sufismo Yerrahi al Halveti; Casa para la Difusión del Islam (Ciudadela); Centro de Altos Estudios Islámicos (Bs. As.); Mezquita At Tauhid (Bs. As.); Organización Islámica 


\section{El desarrollo del campo sufí local}

El desarrollo del sufismo en nuestro país ha tenido diversos orígenes y derivas, pudiendo hallarse grupos fundados en lazos étnicos y otros conformados en su totalidad por conversos locales al Islam y al sufismo. Los grupos que conforman el primer caso son aquellos grupos cuyos iniciadores o su ascendencia pertenece al Islam en alguna de sus ramas. Los primeros grupos sufíes en nuestro país se registrarían a estas características, ligados el ámbito shií, en relación con el arribo de inmigrantes alawies o nusayríes de Siria y Líbano a fines del siglo XIX y comienzos del siglo XX (Kerman, 2007). Actualmente, estos grupos se concentran en la localidad de José Ingenieros (Ciudadela, Gran Buenos Aires) y en algunas provincias del Noroeste argentino, entre otros. ${ }^{7}$

El segundo tipo de formación sufí que mencionamos engloba a los grupos que sin lazos étnicos generaron un desarrollo local del sufismo. Kerman (2007) los menciona como nuevos musulmanes, entendidos como argentinos sin ascendencia árabe que buscaron en la conversión al Islam un camino espiritual ya desde la década de los setenta.

Dentro de este segundo conjunto, podemos a su vez pensar en una corriente del sufismo separada del Islam, así como corrientes «neosufíes», o, según otra división, en corrientes tradicionalistas o innovadoras (Kerman, 2007; Chinnici, s/f). En el análisis realizado en la ciudad de Rosario (Provincia de Santa Fe, Argentina), ha sido posible hallar en un mismo grupo distintos tipos de participación, por lo cual algunas personas asistían a las reuniones sufíes, dikr (remembranza de Dios) sin acompañar esta participación con otra práctica islámica (Salinas, 20 I I).

Argentina (Bs. As); Movimiento Islámico Latinoamericano (Bs. As); Mutual Islámica Comunitaria Argentino Americana (Bs. As.); Instituto Islámico Árabe Argentino (Bs. As.). Para el resto del país se puede mencionar: en Mendoza, Sociedad Árabe Islámica; Sociedad Árabe Islámica; en Tucumán, Asociación Cultural y de Culto Panislámica; en Córdoba, Mezquita Islámica de Córdoba; Comunidad de la Juventud Musulmana; Sociedad de Socorros Mutuos y Ayuda Social Árabe Musulmana; World Assembly of Muslim Youth (WAMY); y en Rosario, Asociación Unión Islámica.

7. Uno caso de estos casos es mencionado por Montenegro (20II), quien explica que el Sheij Alí Al-Husaini (hijo de un sirio alauita y una libanesa) estuvo relacionado desde la década de los setenta primero a la tariqa de Schoun y luego a la de Abdel Qader As-sufi, para formar después su grupo autónomo con sede en San Martín de los Andes. 
En este punto retomamos la discusión presentada por Grimson (2010), quien está interesado en despejar los conceptos de «cultura» e «identidad», y la relación teórica que se teje entre ellos muchas veces. Como sostiene el autor es usual, como resabio de posturas esencialistas, que ambos conceptos sean homologados, haciendo suponer una correspondencia que no siempre es tal. En realidad estas categorías no se acoplan sencillamente sino que, como en algunos casos mencionados por el autor, la proximidad cultural de dos poblaciones genera una acentuación subjetiva de las diferencias identitarias. Esta discusión nos permite iluminar, en nuestro caso, el proceso que da lugar a la articulación de elementos religiosos ajenos a la cultura argentina, integrándose, hilándose a los elementos culturales disponibles, para consolidarse como parte de un sistema identitario de los grupos sufíes locales. Es interesante el concepto que utiliza Grimson (20I0) de «regímenes de articulación de significados» para pensar como distintos sistemas de creencias globales y locales encuentran nuevos códigos para expandirse.

En esas distintas formas de constituirse como agrupación religiosa que mencionamos, es posible reconocer pertenencias y conformaciones identitarias ligadas y entramadas a un sistema cultural remoto, aquellos grupos o sujetos que devienen su identidad religiosa de su pertenencia cultural, como en el caso de los primeros sufíes frutos de migraciones de árabes musulmanes. Habría en este caso una correspondencia entre las categorías de cultura e identidad. La otra forma sufi que presentamos, la de conversos, enlaza su conformación en la cultura local, a partir de reconocer en determinada práctica, elemento o dinámicas de una seña comunal, una marca de pertenencia e identidad. Una tercera forma de pertenencia vuelve a tener como horizonte un sistema remoto, el modelo naqshbandi haqqani de la dergah (lugar de encuentro sufi), madre en Lefke (República Turca de Norte de Chipre).

\section{Tariqa Naqshbandi Haqqani}

La tariqa sufí Naqshbandi ${ }^{8}$ Haqqani tiene origen turco y su genealogía de maestros está compuesta por una cadena de cuarenta santos (walis o maestros)

8. La tariqa Naqshbandi, de la que deviene la Naqshbandi Haqqqani, tuvo origen en Bujará (Uzbekistán) en Asia Central en el siglo XIV con Muhammad Bahauddan Uways al-Bukhari (Shah Naqshband) considerado el I9. ${ }^{\circ}$ Gran Sheij. La misma habría sido un desprendimiento de la tradición mística de los Grandes Maestros, los Khwajaga del siglo XIII al XVI de los oasis de Asia Central (Algar, I976; Weismann, 2007). 
hasta la actualidad. Cada uno de ellos fue considerado Sultán ul Awliya de su época, rango del santo que posee el secreto del Santo Profeta. El último de ellos fue Mawlana Shaykh Nazim Adil Al-Haqqani, (fallecido el 7 de mayo del año 20I4), quien había asumido esta función en el año I972. ${ }^{9}$

Junto con la orden Yerrahí al Halveti,${ }^{10}$ la Naqshbandi Haqqani consolidó su presencia en Argentina a mediados de la década de los noventa, aunque subsisten otros grupos sufíes minoritarios. Esta última se inserta en el país a partir de una red de diversidad religiosa con la que interactúa. Si bien el sufismo se vincula originalmente a la tradición islámica, observaremos que su desarrollo en nuestro país tiene características que la enlazan a una serie de prácticas espirituales que en nuestro contexto han sido denominadas «alternativas». ${ }^{11}$ Su origen, desarrollo y armado local nos permiten indagar en los caminos del sufismo local de conversos.

Se ha observado que en la práctica local el sufismo se constituye desde las intersecciones con otros elementos prácticos y teológicos a veces alejados del Islam, generándose una constelación de elementos que se tornan afines, conectados y organizados con una lógica nueva.

Los primeros grupos sufíes locales de la orden se fueron conformando en principio reunidos alrededor de algunos diacríticos sufíes periféricos, en tanto se interceptan con otras prácticas espirituales, para luego ir consolidando un esquema identitario nuevo que reordena, dota y sopesa nuevamente a sus elementos.

Este proceso que podría parecer caótico para los sujetos en tanto podría interpretarse como una transición, un paso previo hacia un estado de mayor organización, no es vivenciado de esa manera por los propios sujetos.

9. Mawlana Sheyk Nazim nació en Lárnaca (República Turca de Norte de Chipre), el 2 I de abril de I922. Su linaje por parte de padre lo relaciona a Abdul Qadir Gilani, fundador de la Orden Qadiri y el de su madre a Jalaluddin Rumi, fundador de la Orden Mevlevi. Además de ésas, fue iniciado en otras órdenes antes de recibir en I944 la mubay’a del sheik naqshbandi originario de Daguestán, Sheik Abd-al-Llah al-daghestani (m. I973), en Damasco. A la muerte de su maestro, se convierte en líder de la nueva tariqa y continúa sus viajes por Europa y por América del Norte principalmente, e instala la zawiya madre en la parte turca de Chipre.

ıo. La Orden Jerrahi originaria se dividió en dos grupos que permanecen en la actualidad: Yerrahi y Jerrahi.

I I. Una idea similar puede hallarse en Montenegro (2008). 
El primero tiene que ver con que las construcciones identitarias no van a la par, ni contonean la cultura, necesariamente; y asimismo lo hicieren no hay un estado de equilibrio quieto en esas construcciones. Por ello, no hay un «estado de completud sufi argentino» al que arribar.

Ahora bien, hay determinados «regímenes de articulación de significados», determinadas formas en las que se dan esas conjunciones culturales. Pensando en nuestro campo sufi, hay ciertas líneas que se repiten que nos permiten pensar en ciertas «formas de ser sufí» en este país.

Cuando pensamos en la adscripción al sufismo que realizan los sujetos en el ámbito local, nos valemos también de la propuesta de Frigerio (2007), quien cuestiona el concepto de «identidad religiosa porosa» $\mathrm{o}$ «identidad sincrética», con el que pueden analizarse los tránsitos o recorridos individuales y coloca esos adjetivos en el sistema de creencias, en cuanto es este último el que tiene estas cualidades. Los sujetos y su pertenencia son observados en su continuidad e integridad.

\section{La trama cultural en la que se teje la pertenencia sufí local}

Partimos retomando lo sostenido por Oro (2009), quien manifiesta que así como en algunos contextos transnacionales predomina la movilidad espacial de personas a través de las fronteras nacionales (Estados Unidos-México, Europa del Este/Oeste, África del Norte/Europa, etcétera), como en América Latina, prevalece la transnacionalización de productos y prácticas culturales, entre ellos los religiosos. A partir del reconocimiento identitario, la comunidad sufí local que estudiamos comienza un proceso de densificación de la trama cultural haciendo uso de los elementos de los que se dispone. No se trata de un proceso devenido de una comunidad transmigrante, sino como lo llamaría Frigerio (2002) de la generación de un «campo social transnacional», en el que activistas de manera individual motivan el interés de una población local alrededor de una práctica que ha trascendido sus límites de origen. Prácticas y elementos que se translocan adaptándose a nuevos órdenes y significados.

Nos detendremos a continuación en una serie de elementos que hacen a la construcción de la identidad sufí en el contexto local para observar como el sistema sufí local se entrelaza a otros sistemas religiosos. 
Participación del sufismo en las redes espirituales locales

La identidad sufí en el contexto local se entreteje en una red de prácticas alternativas. En la generalidad de los casos sucede que la integración al grupo está mediada por pasos muy graduales, con trayectos de distintas duraciones y se sostiene en una tensión permanente. La forma que adopta el grupo local en su relación con los individuos es abierta, en tanto si bien establece como parte de la pertenencia la realización de determinadas prácticas y deberes a los mismos, permite de manera amplia los distintos trayectos y fluctuaciones en la participación de las reuniones religiosas.

La red de prácticas alternativas está conformada sobre todo por prácticas de origen oriental tales como: tai-chi-chien, tai chi chuan, chikun, Escuela del Cuarto Camino, la meditación zen (zazen), hare Krishna, yoga, etcétera, y otras prácticas de origen regional como la biodanza, experimentación con ayahuasca, o reformulaciones de terapias tradicionales como la psicología transpersonal.

Según lo trabajado por Carozzi (I999), una de las características del movimiento new age, aun en nuestros países, es el intercambio de funciones y de prácticas. Es decir, quien en determinada organización oficia de maestro, en otra lo hará de alumno, existiendo una circulación por distintas prácticas. Podemos pensar esta estructura de circulación como una base cultural elemental sobre la que se ejecuta esta dinámica de incorporación de los murids (discípulos) a la tariqa.

Entre las formas generales de arribar a la tariqa rosarina que se fueron cristalizando, se ha hallado un psicólogo transpersonal murid, que a determinados pacientes convidaba asistir a alguna de estas reuniones. Esta forma de entrada no se encuentra en vigencia en la actualidad en tanto el mencionado psicólogo abandonó esta profesión, aunque no su participación en la tariqa. Otra forma de llegada son las respiraciones holotrópicas llevadas a cabo en Argentina por otro miembro sufí. Las mismas fueron la puerta de entrada de numerosos miembros que fueron luego personalmente convidados a asistir a los dikr. Una tercera vía está constituida por los seminarios de eneagrama realizados por sheiks sufíes argentinos y extranjeros. Estos últimos eran y son una de las instancias de iniciación en el sufismo, donde se posibilita tomar bayad ${ }^{12}$

I 2. La ceremonia de tomar bayad implica para los miembros sufíes tomar compromiso con un maestro para el seguimiento del camino espiritual sufí. 
y pedir un nombre como miembro iniciado en la Orden Naqshbandi Haqqani. Por fuera de estas formas institucionalizadas, existe además la posibilidad de ser convidado por un miembro a participar en alguna reunión.

En definitiva, podemos entrever de manera esquemática dos vías para llegar al sufismo, la más extendida es la ya referida, que reúne a aquellos exploradores de "prácticas espirituales» de un amplio espectro. La otra, proviene del interior de la religión islámica, en cuanto la adherencia al Islam es anterior a la adherencia al sufismo. Se entiende al sufismo como un camino de refinamiento espiritual de la previa pertenencia al Islam. Esta manera de conceptualizar el sufismo es a la que adscribe la minoría naqshbandi, por lo que recalcan que esta expresión religiosa es ante todo una expresión islámica, a la que no se puede comprender realmente si primero no se conoce plenamente la doctrina islámica, en tanto el sufismo se trataría de la culminación de un proceso imposible de aprehender si no se cuenta con esas bases. Esta opción puede producirse a partir de fieles que en primera instancia se acercan al Islam como un todo, para luego «profundizar» en el sufismo.

\section{El horizonte de búsqueda del «maestro verdadero»}

Sin duda, como un desprendimiento de la configuración en redes espirituales es posible observar en la búsqueda del «maestro verdadero» otros de los elementos que contribuyeron al armado del sufismo local. Según se registra en las distintas narraciones de la conformación de las turuq, un líder espiritual (maestro) flexibiliza su posición pasando de una función a otra, para convertirse en discípulo de otro. Esta nueva configuración arrastra a toda la comunidad a una nueva situación.

Este es uno de los elementos que intersectan las prácticas espirituales y que van delineando el sentimiento de pertenencia y la construcción de una identidad sufí local.

En los casos abordados, la búsqueda del «maestro verdadero» ofició como nexo entre la Escuela del Cuarto Camino y el sufismo local. La idea de que se precisa un ser humano ejemplar que actúe como guía, y que sea reconocible emocionalmente, a "simple vista», permite el enlace de una práctica a otra.

Según fue relatado por uno de los representantes de la Orden en Argentina, el primero en tomar contacto con Mawlana Sheik Nazim al Haqqani fue un 
psiquiatra de Mar del Plata que conducía una Escuela del Cuarto Camino. ${ }^{13}$ Esta persona en el año I 985 , viajando por el Norte de África, tomó contacto con musulmanes y con algunas órdenes sufíes. Luego, recorriendo Turquía conoció a un discípulo de la orden Mevlevi y al sentirse muy impresionado por esta persona pidió conocer a su sheik. El discípulo le dijo que su sheik no era el sheik para él, que su sheik sería Sheik Nazim. Ya durante la década de los noventa, el psiquiatra viajó a Chipre y se hizo discípulo de Mawlana. Luego, y a pedido del maestro se publicó un libro en el que se difundieron una serie de charlas dadas por el líder de la orden. Esta fue la forma en la que sus alumnos de la Escuela del Cuarto Camino fueron conociendo y, en alguno de los casos, convirtiéndose a la tariqa.

Por su parte, el psiquiatra y difusor original de la orden en el país transmite la novedad en Glew, provincia de Buenos Aires, a partir del contacto con otro profesor de la Escuela del Cuarto Camino. A los miembros de este grupo, originalmente practicantes de tai-chi-chien y chikun, su profesor les anuncia que había encontrado en el sufismo un camino que trabajaba un chakra más sutil, como el del corazón, a diferencia del trabajado hasta entonces, el tan-tien (generalmente ubicado dos o tres centímetros debajo del ombligo). El punto de inicio en este nuevo grupo es Mar del Plata. Allí se convierten al sufismo cuatro personas. A partir de este pequeño grupo se inicia la tariqa de esta localidad, y se da comienzo a la construcción de la mezquita.

De la misma forma, uno de aquellos ejemplares llegó a las manos de un maestro de tai chi chuan en San Lorenzo en la provincia de Santa Fe. Según el relato de uno de los miembros de la tariqa rosarina, los miembros de este grupo de practicantes, entre los que había rosarinos, repitiendo el modelo de conversión grupal ya mencionado, y comandados por el maestro, se vuelcan a la búsqueda de un camino espiritual en tanto se ven necesitados de algo que no está siendo colmado con la actividad que estaban desarrollando. Así toman contacto con las enseñanzas de la doctrina del cuarto camino.

En este contexto de búsqueda espiritual grupal, se encuentran con un texto que establecía que los maestros chinos en la antigüedad no transmitían la disci-

I3. Según explicó un miembro de la Naqshbandi de Rosario, la doctrina de la Escuela del Cuarto Camino y su difusor en occidente, George Gurdjíeff, están vinculados con el sufismo en tanto Gurdjíeff habría accedido al secreto del eneagrama. Pese a esta transmisión no se le autorizó a transmitirlo, así que sus discípulos tuvieron que recrear de manera autónoma ese conocimiento para mantenerlo vivo en una tradición. 
plina a sus discípulos a no ser que se hicieran musulmanes. Ello es interpretado como una señal y deciden viajar a Mar del Plata, donde se hallaba el representante de la orden Naqshbandi en Argentina en ese momento (el mencionado psiquiatra). Del grupo que viajó, siete miembros se inician en la orden sufí Naqshbandi.

Junto con el sufismo, y convocados por el profesor de tai chi chuan, comienzan a practicar también danzas circulares ${ }^{14} \mathrm{y}$ algunos miembros del grupo también son iniciados en el taoísmo y en la escuela de yoga Ananda Marga.

En el año I990 comienzan formalmente las reuniones de la orden en San Lorenzo. Y en el año I995 construyen con sus propias manos la sala de oraciones en esa localidad. En esta ciudad se reunían entre tres y cuatro veces por semana, por lo que, en un momento, el actual Sheik rosarino pidió que se separaran las jurisdicciones, por lo que las reuniones comienzan a realizarse en casas de integrantes de la orden rosarina.

La búsqueda del "maestro verdadero» funciona como un diacrítico que amplia y redefine los límites y la red de significaciones que organizan al grupo. El propio maestro de la Escuela del Cuarto Camino reconoce en otro la cualidad del «verdadero maestro», y con ello conduce a sus alumnos a reconocer la valía del segundo sobre sí mismo. Si pensamos al diacrítico como la marca de la frontera del grupo religioso en relación a otros, entonces se trata de una marca móvil, flexible y cambiante, conformando redes de creencias fluidas, con canales comunicantes.

\section{El encuentro de la comunidad}

Otros elementos identificatorios de las agrupaciones sufíes locales son incorporados con la misma dinámica progresiva y aleatoria, tal como el «maestro verdadero». En los primeros tiempos de la tariqa argentina, a fines de la década de los ochenta, los miembros de la comunidad marplatense que comenzaron a participar de las reuniones, seguían participando también de las reuniones del Cuarto Camino. No habían incorporado aún uno de los marcadores identitarios de los naqshbandi haqqani en tanto aún no usaban la vestimenta típica de la orden, ${ }^{15}$ ni realizaban la reunión semanal propia de los sufies, el dikr. Cons-

I4. Psicoterapeutas gestálticos son los que pasan las primeras coreografías al grupo de danzas circulares.

I 5. La misma consiste en el caso de los hombres en pantalones anchos (shalwar), 
truían una secuencia ritual ad-hoc, tomando como base una cinta de grabación que el iniciador de la tariqa había hecho a Chipre en un único viaje de diez días de duración. Sobre esa grabación y desconociendo el idioma árabe, repetían lo que escuchaban, intentando pronunciar algo parecido a lo que oían.

Según expresan, los unía la intención de encontrarse en comunidad. Todos los elementos y actividades con los que fueron llenando este espacio de encuentro fueron siendo significados paulatinamente. Cómo advierte un sheik, en realidad no era importante para qué se reunían, qué ropa vestían, qué palabras o sonidos repetían. Si se hubiera tratado de la repetición de un texto en japonés en vez del árabe hubiera implicado lo mismo: la posibilidad de sostener el encuentro. Observamos aquí que la constitución del grupo se sostiene en su analogía con una dinámica preexistente, ya conocida por todos en cuanto miembros anteriores de otras comunidades espirituales.

Esta interpretación de la práctica sufí descrita no puede ser observada como una improvisación defectuosa, ni incompleta como mencionamos antes. Sólo podría verse de esta manera si intentáramos explicar las transformaciones de los grupos de creencias en tanto cismas de una vertiente original poseedora de una identidad esencial, que luego se diluye en ramas más débiles e informes. Es lo que antiguas teorías pensarían como la distinción entre iglesias y denominaciones, pensando a las primeras como instituciones más formalmente establecidas y a las segundas como derivaciones de aquéllas, volátiles y sin peso social.

\section{La configuración inserta en redes transnacionales}

Los procesos de entramado con la cultura preexistente que desarrollan las comunidades sufíes en Argentina, se ven reorientados con el crecimiento de las redes y vías de comunicación de la comunidad global de la tariqa. Estas redes comienzan a componer parte de los límites y líneas de existencia de estas comunidades, aportando contenido a cada una de ellas. Lo que observábamos como procesos más o menos experimentales, se vuelven decididamente orientados en su contenido y forma y se enlazan como parte de un esquema expansivo global promovido por la tariqa, por lo que estaríamos ante otro modelo de transnacionalización, en el que se contactan sistemas religiosos culturales diferentes, y ya no la introducción al sistema local de elementos arbitrariamente incorporados.

camisas amplias y turbante que rodea un cono, y en el caso de las mujeres, ropas amplias y con un pañuelo que les cubre el cabello. 
Para abordar esta forma de conformación sufí, nos valemos de una de las variantes de transnacionalización que plantea Vertovec (I999), entendida como la (re)construcción del «lugar» o localidad a partir de prácticas y significados derivados de puntos geográficos e históricos específicos transferidos y reterritorializados. ${ }^{16} \mathrm{El}$ autor enfatiza el alto grado de movilidad humana, telecomunicaciones, filmes, videos y televisión satelital e internet que han contribuido a la creación de convergencias translocales.

Las comunidades de Mendoza y Río Negro en Argentina nos permiten visualizar este proceso. Las mismas han consumado de manera más aproximada el modelo ideal propuesto y ejecutado en Chipre.

\section{Circuito de viajes y redes de internet}

La densidad de los elementos religiosos transnacionalizados fueron aumentando en tanto la frecuencia de los viajes de los murid y la red de internet fueron transformando al interior del grupo las maneras de hacer las cosas. Hoy en día, la apariencia de un miembro naqshbandi haqqani de Argentina o de España es la misma que se encuentra en Chipre. Por un lado, la tariqa ha invertido en una franca expansión, siendo los viajes parte de la tarea de los representantes que circulan permanentemente entre las dergahs y centros que conducen y la visita de la dergah madre (y antes al maestro) en Lefke, conformando para Haddad (2008) una "cofradía globalizada». Por otra parte, se han aceitado las vías de acceso a una gran cantidad de datos en comparación con los primeros viajes realizados por los iniciadores de las turuq. Como mencionábamos antes, este proceso de transnacionalización no se ejecuta de manera directa, sino que el entramado cultural torna singularmente propios los modelos reterritorializados. El caso de la vestimenta típica de esta orden es un claro ejemplo de este movimiento, poniéndose en juego en la práctica en la aceptación o no del uso de dichas vestimentas por parte de los murids locales, en la curiosidad generada entre los vecinos de los pequeños pueblos donde se instalan, en la caricaturización por parte de la comunidad de estos «hombres con turbante» $\mathrm{y}$ «mujeres con pañuelos en la cabeza».

Internet cobra una importancia fundamental para el sistema de redes de esta tariqa en tanto los miembros de todo el mundo, sobre todo para quienes

I6. Se trata de una entre otras conceptualización de transnacionalización que presenta el autor en el texto referido. 
habitan en el continente americano y no pueden acceder a Lefke con la misma frecuencia que lo pueden hacer los europeos a Chipre.

Las páginas web, y sobre todo la página oficial de la tariqa (saltanat.org) se constituyen en un archivo de permanente renovación en el que pueden encontrarse sohbet o jutbas brindadas por el maestro. Este uso dado a la web por un lado provee una corriente de material de la que se abastecen las distintas turuq Naqshbandi Haqqani, sobre el que se toman decisiones en los grupos locales siguiendo la línea marcada por el maestro, no libres de disenso e interpretaciones varias.

La web es un instrumento utilizado casi de manera regular actualmente por la mayoría de los miembros. Esto es, las vías de acceso y conocimiento de la tariqa no se dan en su gran mayoría a partir de búsquedas en internet, sino que el uso de la web se constituye en otro de los elementos que conforman la participación en la tariqa. En tanto comienzan a acercarse a la tariqa, comienzan también a interactuar por y con la web visitando sitios relacionados con la misma y estableciendo contactos con otros miembros de la tariqa de otras dergahs.

\section{Establecimiento en ambientes agrestes}

Las comunidades Naqshbandi Haqqani de la Consulta (Mendoza) y del Bolsón (Río Negro), ${ }^{17}$ forman parte de una serie de comunidades establecidas en ambientes agrestes en todo el mundo, resultado del pedido de Mawlana a sus discípulos de llevar una vida en comunidad, alejada del ritmo de vida que implican las grandes ciudades, asemejándose de alguna manera a los estándares de vida que se llevan a cabo en Lefke. Este pedido fue acentuado cuando se sostenía la creencia de la precipitación del Apocalipsis, y la necesidad de resguardarse de peligros naturales y guerras. La comunidad del Bolsón fue una de las primeras comunidades en conformarse en Argentina ya que data de los primeros días de diciembre de I999. Se halla situada en la localidad de Mallin Ahogado, a unos $20 \mathrm{~km}$. de la ciudad de El Bolsón (Río Negro). Por su parte, la comunidad localizada en Mendoza se originó en el año 200 I y al año siguiente las primeras familias comenzaron a establecerse.

La (re)localización de las prácticas sufíes por estas tierras se enmarca en

I7. Existen otras comunidades en Argentina de este tipo más pequeñas: San Esteban y Potrerillos (Mendoza) o San Estevan (Córdoba). 
una estética y lógica espacial que también se toma del modelo de Lefke. Sea tanto el lugar elegido para erigir las comunidades, la organización espacial, la administración de los distintos espacios, como la orientación de los edificios, y por supuesto todas las actividades que se realizan en ellas van a estar orientados por las indicaciones del maestro, transmitidas a partir de la voz de sus diputados locales.

La comunidad de La Consulta, ubicada a orillas de la ruta, ocupa 27 hectáreas y cuenta con vertientes de agua naturales. El mismo año de instalación, y por indicación del maestro se comenzó la construcción del maqam (estación espiritual, «lugar» en árabe) de un venerado maestro de la línea, Gran Sheik Abdullah al-Fa'iz ad-Daghestani, cuya orientación geográfica y ubicación de la entrada también fue indicado por el propio Mawlana, quien realizó un pequeño diseño en un papel y se lo entregó al representante de Argentina en ese momento. En el caso de la comunidad patagónica, que cuenta con 23 hectáreas, según se menciona en la página web (patagoniasufi.com.ar), el sheik a cargo consultó con el maestro el lugar más adecuado para construir una mezquita y asentar la comunidad.

En ambos casos, las construcciones de las comunidades están realizadas con materiales de la zona, ya que ésa fue una de las indicaciones del maestro. La dergah austral fue construida con materiales naturales de la zona, en este caso madera de ciprés y piedra y, en el caso mendocino, la mayoría de las viviendas están construidas en madera y adobe.

\section{El carácter migrante}

Tanto en la localidad mendocina como en la rionegrina, se hallan los líderes de la Naqshbandi Haqqani en Argentina. Reconocidos ambos por el propio maestro. Dicho reconocimiento doble no estuvo librado de disputas al interior de los grupos nacionales, pese a las cuales han logrado desarrollar comunidades estables a su alrededor.

En la actualidad estas comunidades están conformadas por una serie de familias provenientes de distintos puntos del país. En la de Mendoza la cantidad ronda las veinte familias, mientras la comunidad de la Patagonia reúne a menos de diez familias. Asimismo, hay algunos miembros o familias que no viven permanentemente allí, sino que tienen una residencia más irregular, permaneciendo períodos allí, y otros en sus lugares de origen. La característica migrante de estas familias es otro de los elementos tomados del modelo turco. 
Era común que el maestro indicara a sus murids y sus familias trasladarse si consideraba que en algunas zonas estaban en peligro por algún motivo, ya sea por la presencia de conflictos bélicos o porque los lugares no estaban bendecidos.

La movilidad regular tiene que ver además con el espíritu de expansión llevado a cabo por los diputados o difusores del sufismo. Pueden tratarse de viajes regulares para visitar al maestro (mucho más acentuado en el caso de los líderes que por cercanía geográfica pueden viajar varias veces en el año a Lefke), como aquellos emprendidos por quienes realizar charlas y talleres de difusión relativos al sufismo y a la tariqa.

Todas las turuq Naqshbandi tienen una casa de huéspedes o algún espacio de la dergah destinado a la gente que está de paso. Además de la característica migrante puede observarse una marcada hospitalidad con el murid viajero.

\section{El trabajo en la cosmovisión sufí}

Las actividades laborales de los miembros de las comunidades están vinculadas muchas a servicios y terapias alternativas que los murids realizan por cuenta propia. En el caso de Mendoza, actividades tales como: reiki, yoga, medicina homeopática, terapia gestált, constelaciones familiares, así como tareas de profesores, maestros, gasistas, artesanos, jardineros, masajistas, profesores de pilates y astrólogos, construcción de cabañas para el turismo y producción de miel. Por su parte, la comunidad de la Patagonia, organizada alrededor de la familia del sheik, se dedica a la cría de animales: cabras, ovejas, vacas, asnos, conejos, aves y caballos. Según la información que presentan en la web, poseen un piño de cabras lecheras de razas Tohenburgh, Sannen y Alpinas, además de sembrar y producir distintos tipos de alimentos. De lo que consumen el ı००\% de su consumo de carne hallal y lácteos caprinos.

En general, las actividades laborales de los miembros Naqshbandi no son en relación de dependencia. Esto se debe a que les permite congeniar con mayor facilidad el trabajo con las obligaciones religiosas como sufíes, tales como la realización del salat, la asistencia a los dikr y al juma'a los días viernes. Además, el comercio es muy bien considerado en esta orden y recomendado por Mawlana por ser considerado sunna, en tanto se sostiene que el profeta se dedicaba al comercio. En el caso de la comunidad del sur, la cría de animales fue también una indicación del maestro.

Observamos en todas estas incorporaciones locales del modelo sufí prescrip- 
to desde Lefke un alejamiento de la dinámica que observábamos en el segundo momento, en los orígenes de las órdenes sufíes de conversos locales. Con la incorporación progresiva de nuevos elementos a las comunidades locales, se va densificando la estructura identitaria sufí local y densificando también el entramado de sistema de creencias y prácticas en este contexto. El seguimiento de modelo ideal no se presenta como una totalidad que se apoya sobre el vacío, sino que la progresión y variabilidad con que se ejecuta esta transferencia y reterritorialización se da en tanto un sistema que entra en relación con otro.

\section{Reflexiones finales}

En el presente trabajo abordamos la construcción de la pertenencia de los grupos sufíes Naqshbandi Haqqani en el entramado cultural de Argentina. Para ello nos hemos valido de las líneas de relato histórico de las distintas turuq nacionales, observándolas a su vez en perspectiva diferencial con respecto a las agrupaciones sufíes étnicas venidas con las grandes migraciones de países árabes.

Para problematizar esta construcción retomamos discusiones sobre la relación entre la cultura y la identidad, o más bien sobre la dislocación de esa relación.

La cultura, como estructura de cimientos, aparece en nuestro recorrido de diferentes maneras. En los primeros grupos sufíes nacionales, la adscripción religiosa étnica coloca a la cultura como la base de esa pertenencia. Se es sufí porque primero se es de una comunidad árabe musulmana.

En los grupos surgidos en el país, en tiempos recientes, los elementos culturales se conjugan de manera diferente. La apropiación por parte de estos grupos de lo que llamamos diacríticos sufíes y la construcción de la pertenencia identitaria se apoya en los marcos culturales locales. Estos procesos de constitución de comunidades locales no pueden pensarse escindidos de los procesos de transnacionalización religiosa. Procesos presentes en un primer momento a partir de la transnacionalización de prácticas y elementos sufíes movidos por activistas predominantemente individuales que alimentaron el circuito espiritual local. En un tercer momento los procesos de transnacionalización tienen lugar como (re)localización o construcción del «lugar» a partir de prácticas y significados derivados de puntos geográficos e históricos específicos transferidos y reterritorializados. Es lo que observábamos en las comunidades de Mendoza y Río Negro. 
Las comunidades sufíes argentinas son moldeadas por la pertenencia a redes cuyos nodos originales se hallan temporal, espacial y simbólicamente muy alejados del contexto local. La apropiación de prácticas y símbolos de la Orden Naqshbandi Haqqani, se desarrolla sin licuar el sello local, densificando el entramado cultural, poniendo en juego elementos que actúan como índices de identidad, o adoptando modelos relocalizados. Dicha apropiación guarda una lógica en todo el proceso al interior de la comunidad que permite ir delineando el círculo de pertenencia local.

\section{Referencias}

Algar, Hamid (1976). "The Naqshband Order: A Preliminary Survey of Its History and Significance». En Studia Islamica, 44: I23-I 52. Disponible en $<$ http://www.jstor.org/stable/I 595445>.

Akmir, Abdeluahed (20I I). Los árabes en Argentina. Rosario: UNR Editora. Álvarez, Horacio (2003). «Islámicos». En Floreal Forni y otros (compiladores), Guía de la diversidad religiosa de Buenos Aires. Buenos Aires: Biblos.

Bianchi, Susana (2009). Historia de las religiones en Argentina. Las minorías religiosas. Buenos Aires: Sudamericana.

Carozzi, María Julia (i999). «La autonomía como religión: la Nueva Era». Alteridades, 9 (I8). Universidad Autónoma Metropolitana, Itztapalapa: Distrito Federal.

Chinnici, Fernando (s/f). Sufismo porteño. El caso de la 'Dergah de Murillo'. Buenos Aires, Argentina.

Clifford, James (I999) [1997] «Prólogo: In media res». En Itinerarios Transculturales. Gedisa: Barcelona.

Frigerio, Alejandro (2013). «Nuestra elusiva diversidad religiosa: Cuestionando categorías y presupuestos teóricos». En Corpus, 3 (2). Disponible $<$ http:// corpusarchivos.revues.org/3 I3 $>$.

-. (2007). «Repensando el monopolio religioso del catolicismo en Argentina». En María Julia Carozzi y César Ceriani (eds.) (2007), Ciencias sociales y religión en América Latina: Perspectivas en debate (pp. 87-I I 8). Buenos Aires: Biblos/ACSRM.

-. (2002). «La expansión de religiones afrobrasileñas en Argentina: representaciones conflictivas de cultura, raza y nación en un contexto de integración regional». En Archives de Sciences Sociales des Religions, II7. Disponible en $<$ http://assr.revues.org/index2489.html>. 
Grimson, Alejandro (2010). «Cultura, identidad: dos nociones distintas». Social Identities, I 6 (I): 63-79.

Haddad, Moulud (2008). «Zawiya réelle, Zawiya virtuelle, soufisme, francophonie et nouvelles technologies au Québec». Globe. Revue Internationale d'Etudes Québécoises, Io/I I.

Kerman, Analía (2007). Construcción de la subjetividad ascética: estudio etnográfico de un grupo sufí- islámico en Buenos Aires. Tesis de Licenciatura, Universidad Nacional de Buenos Aires.

Mallimaci, Fortunato (compilador) (2013). Atlas de las creencias religiosas en la Argentina. Buenos Aires: Biblos.

Montenegro, Silvia (20I I). «Redes del Islam shiita en Argentina». IX Reunião de Antropologia do Mercosul, ro a I 3 de Julho, Curitiba.

-. (2009). "Instituciones, identidades y membresía». Disponible en <http:// lacc.fiu.edu/research/islam-in-latin-america/working-papers/islam_in_argentina.pdf $>$.

-. (2008). "Contextos locales y expresiones contemporáneas del Islam». En Modernidad, religión y memoria. Buenos Aires: Colihue.

Oro, Ari Pedro (2009). «Transnacionalización religiosa en el Cono-Sur: una comparación entre pentecostales y afro-brasileros». En Debates do NER, Porto Alegre, Io (I 6): 225-245.

Salinas, Lucía (20 I I). «La orden sufi naqshbandi en el campo religioso de la ciudad de rosario». IX Reunião de Antropologia do Mercosul, IO a I 3 de julho de 20I I, Curitiba, PR.

Vertovec, Steven (I999). "Minority associations, networks and public policies: re-assessing relationships». En Journal for Migration and Ethnic Studies, 25 (I).

Weismann, I. (2007). The Naqshbandiyya. Orthodoxy and activism in a worlwide Sufi tradition. Routledge: Nueva York.

\section{Sobre la autora}

Lucía Amparo E. Salinas es Licenciada en Antropología de la Universidad Nacional de Rosario. Actualmente se encuentra cursando el doctorado en $\mathrm{Hu}$ manidades con mención en Antropología en la misma universidad y efectúa tareas docentes en UADER. Su correo electrónico es <lu.salinas@gmail.com>. 